\title{
Nonmetastatic Castration-Resistant Prostate Cancer
}

\author{
Jun Hyuk Hong, Isaac Y. Kim ${ }^{1}$ \\ Department of Urology, University of Ulsan College of Medicine, Asan Medical Center, Seoul, Korea, ${ }^{1}$ Urologic Oncology, Rutgers Cancer \\ Institute of New Jersey, New Brunswick, NJ, USA
}

\begin{abstract}
After the introduction of prostate cancer screening with the prostate-specific antigen (PSA) test, we have witnessed a dramatic stage migration. As a result, an increasing number of patients are diagnosed at earlier stages and receive local treatments including surgery or radiation. When these local treatments fail by the definition of increasing PSA levels, patients are usually treated with androgen-deprivation therapy. A fraction of these patients will finally reach a state of castration-resistant prostate cancer (CRPC) even without radiological evidence of metastasis, which is referred to as nonmetastatic CRPC (NM-CRPC). Most men with advanced or metastatic prostate cancer initially respond to various types of androgen ablation, but a considerable portion of them eventually progress to NM-CRPC. Among patients with NM-CPRC, about one-third will develop bone metastasis within 2 years. In these patients, PSA kinetics is the most powerful indicator of progression and is usually used to trigger further imaging studies and enrollment in clinical trials. Although CRPC remains largely driven by the androgen receptor, the benefit of second-line hormonal manipulations, including first-generation antiandrogens, adrenal synthesis inhibitors, and steroids, has not been investigated in men with NM-CRPC. To date, denosumab is the only agent that has been shown to delay the onset of bone metastasis. However, overall survival did not differ. In treating NM-CRPC patients, physicians should recognize the heterogeneity of the disease and acknowledge that the recently approved second-line treatments have been studied only in advanced stages of the disease.
\end{abstract}

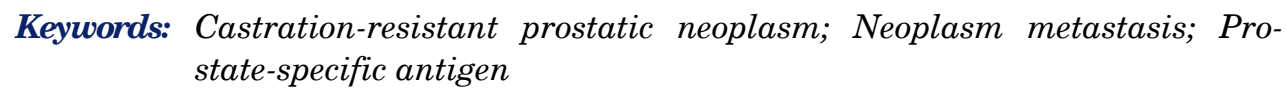

This is an Open Access article distributed under the terms of the Creative Commons Attribution Non-Commercial License (http://creativecommons.org/licenses/by-nc/3.0) which permits unrestricted non-commercial use, distribution, and reproduction in any medium, provided the original work is properly cited.
Article History:

received 22 January, 2014

accepted 22 February, 2014

Corresponding Author:

Isaac Y. Kim

Section of Urologic Oncology,

Rutgers Cancer Institute of New

Jersey, Rutgers, The State

University of New Jersey, 195

Little Albany Street, New

Brunswick, NJ 08903-2681, USA

TEL: +1-732-235-2043

FAX: +1-732-235-6596

E-mail: kimiy@cinj.rutgers.edu

\section{INTRODUCTION}

Prostate cancer $(\mathrm{PCa})$ is the most common solid organ malignancy in men in many western countries including the United States [1] and is the fifth most common in Korean males [2]. After the introduction of PCa screening programs using the prostate-specific antigen (PSA) test, there has been a dramatic stage migration over the past two decades [3]. As a result, an increasing number of patients are diagnosed at an early stage and receive local treatments including surgery or radiation. When biochemical recurrence defined as increasing PSA levels occurs after such definitive local treatments, patients are considered to have systemic disease and are usually treated with early an- drogen-deprivation therapy (ADT). A significant fraction of these men will eventually develop castration-resistant prostate cancer (CRPC) without clinical or radiological evidence of metastasis [4].

Morbidity from $\mathrm{PCa}$ is typically the result of metastatic CRPC. The median survival for men with metastatic CRPC has been not more than 2 years, which is much poorer than that for men with nonmetastatic CRPC (NM-CRPC). According to this observation, NM-CRPC should be differentiated from metastatic CRPC. In addition, there are significant differences in concepts relating to ADT between western and Asian countries. As Akaza [5] described, in western countries, ADT is usually recommended in advanced or metastatic cancer. On the other hand, in Asia, 
ADT is commonly used in nonmetastatic localized cancer. In short, NM-CRPC is mostly the result of off-label use of primary or salvage ADT in patients with PSA progression without evidence of metastases. In this review, we summarize the definition, clinical courses, and emerging treatments in men with NM-CRPC.

\section{DEFINITION OF NM-CRPC}

Although identifying individuals with CRPC may seem relatively clear to treating physicians, defining the disease in epidemiological terms is not straightforward. This confusion may be attributed to the heterogeneity of the disease and the various terminologies, which include CRPC, HRPC (hormone-refractory), AIPC (androgen-independent), and ERPC (endocrine-resistant) [6,7]. Given this confusion, it is important to differentiate castrate-resistant but still hormone-sensitive PCa (i.e., CRPC) from true HRPC. CRPC responds to secondary hormonal manipulations, whereas true HRPC is resistant to all hormonal treatments.

NM-CRPC refers to a rising PSA level under ADT with a castration level of testosterone in the absence of clinically detectable metastatic disease. The recently updated European Association of Urology guideline aims to standardize CRPC diagnosis and includes the following five defining factors [8]:

(1) Castration serum levels of testosterone (testosterone $<50 \mathrm{ng} / \mathrm{dL}$ or $<1.7 \mathrm{nmol} / \mathrm{L})$.

(2) Three consecutive rises of PSA, 1 week apart, resulting in two $50 \%$ increases over the nadir, with PSA more than $2 \mathrm{ng} / \mathrm{mL}$.

(3) Antiandrogen withdrawal for at least 4 weeks and 6 weeks for flutamide and bicalutamide, respectively.

(4) PSA progression, despite continued hormonal manipulations.

(5) Progression of osseous lesions: progression or appearance of two or more lesions on bone scan or soft tissue lesions using the Response Evaluation Criteria in Solid Tumors and with nodes $>2 \mathrm{~cm}$ in diameter.

On the basis of this guideline, PSA serum levels should be higher than $2 \mathrm{ng} / \mathrm{mL}$ before treatment to ensure correct interpretation of therapeutic efficacy. For patients who manifested disease progression solely as a rising PSA level, the Prostate Cancer Clinical Trials Working Group (PCWG2) similarly required a PSA value of $2.0 \mathrm{ng} / \mathrm{mL}$ as the minimum starting level in 2007 [4]. Initially, this requirement was $5.0 \mathrm{ng} / \mathrm{mL}$ in 1999 [9]. The PCWG2 currently defines PSA-only failure as follows [4]:

-A rising PSA that is $2 \mathrm{ng} / \mathrm{mL}$ higher than the nadir with a rise of at least $25 \%$ over nadir.

-The rise must be confirmed by a second PSA at least 3 weeks later.

-The patient must have castration levels of testosterone $(<50 \mathrm{ng} / \mathrm{mL})$.

-No radiographic evidence of metastatic disease.

To date, an overwhelming majority of the clinical trials on NM-CRPC have followed the PCWG2 definition.

\section{CLINICAL COURSES}

Data are lacking on the proportion of patients with NM-CRPC compared with CRPC. In a systematic review of CRPC, Kirby et al. [6] identified 12 articles with a total of 71,179 patients observed for up to 12 years. The data indicated that $10 \%$ to $20 \%$ of PCa patients develop CRPC within approximately 5 years of follow-up and that $16 \%$ of these patients show no evidence of bone metastasis at the diagnosis of CRPC. Of these NM-CRPC patients, 33\% developed bone metastasis within 2 years.

Additional outcome data on NM-CRPC can be obtained from the placebo groups of trials. Smith et al. [10] reported on the natural history of NM-CRPC patients in the placebo group of zoledronic acid and atrasentan studies [11]. At 2 years, $33 \%$ and $46 \%$ of NM-CRPC patients developed bone metastases, and $21 \%$ and $20 \%$ died, respectively. Median bone-metastasis-free survival (BMFS) was 30 months and 25 months in the control group of NM-CRPC patients on the zoledronic acid and atrasentan trials, respectively. These results suggest that that NM-CRPC is a heterogeneous disease that progresses relatively slowly with a median BMFS of longer than 2 years.

With the development of newer imaging techniques including metabolic imaging by positron emission tomography, positron emission tomography/computed tomography, and magnetic resonance imaging, it is likely that metastatic lesions that cannot be detected with the present modalities will be identified. Currently, $(99 \mathrm{~m}) \mathrm{Tc}$ bone scan, which is the standard test used to rule out bone metastasis, lacks specificity and sensitivity [12]. Therefore, the more recent imaging modalities will impact the incidence and natural history of NM-CRPC. In an aborted clinical trial with zibotentan in patients with NM-CRPC, the most common reason for screening failure was the detection of metastatic disease in $32 \%$ of all screened patients [13].

\section{PROGNOSTIC FACTORS}

The natural history of NM-CRCP patients was reported by using the data of placebo groups from the zoledronic acid trial [10]. A baseline PSA level $>10 \mathrm{ng} / \mathrm{mL}$ and a high PSA velocity independently predicted shorter time to first bone metastasis. Patients with a PSA doubling time (PSA-DT) of $<6$ months were those most likely to develop bone metastasis. More recently, Smith et al. [11] reported the natural history of the placebo group of another NM-CRCP study with atrasentan. In multivariate analyses, a baseline PSA $\geq 13.1 \mathrm{ng} / \mathrm{mL}$ was associated with shorter time to first bone metastasis and overall survival (OS).

In a recent subgroup analysis of the denosumab study [14], a shorter PSA-DT was associated with an increased risk of bone metastasis and death. In the placebo group, PSA-DT $<8$ months portended shorter BMFS $(22.4$ months for PSA-DT $\leq 10$ months, 18.7 months for PSA-DT 
TABLE 1. Key trials with new agents in nonmetastatic castration-resistant prostate cancer

\begin{tabular}{|c|c|c|c|c|}
\hline Drug & Mechanism of action & Study design & Primary end point & Outcome \\
\hline Zoledronic acid [10] & Bisphosphonate & Zoledronate vs. placebo & $\begin{array}{l}\text { Time to first bone } \\
\text { metastasis }\end{array}$ & $\begin{array}{l}\text { Terminated early (low } \\
\text { event rate) }\end{array}$ \\
\hline Atrasentan [35] & $\begin{array}{l}\text { Endothelin-A receptor } \\
\text { antagonist }\end{array}$ & Atrasentan vs. placebo & TTP (onset of metastasis) & No improvement \\
\hline Zibotentan [36] & $\begin{array}{l}\text { Endothelin-A receptor } \\
\text { antagonist }\end{array}$ & Zibotentan vs. placebo & PFS, OS & Terminated early \\
\hline Denosumab [37] & $\begin{array}{l}\text { Anti-RANK ligand } \\
\text { monoclonal antibody }\end{array}$ & Denosumab vs. placebo & BMFS, OS & $\begin{array}{l}\text { Improved BMFS ( } 29.5 \mathrm{mo} \\
\text { vs. } 25.2 \mathrm{mo} \text { ), no } \\
\text { improvement in OS }\end{array}$ \\
\hline Enzalutamide [44] & Antiandrogen & $\begin{array}{l}\text { Enzalutamide vs. } \\
\text { placebo }\end{array}$ & MFS & Ongoing \\
\hline ARN-509 [45] & $\begin{array}{l}\text { Androgen receptor } \\
\text { antagonist }\end{array}$ & ARN-509 vs. placebo & MFS & Ongoing \\
\hline Orteronel (TAK-700) [47] & 17,20-lyase inhibitor & Phase II & $\begin{array}{l}\text { PSA response rate (PSA } \\
\leq 0.2 \mathrm{ng} / \mathrm{mL} \text { after } 3 \mathrm{mo})\end{array}$ & Completed, no report \\
\hline Bevacizumab [53] & $\begin{array}{l}\text { Anti-VEGF } \\
\text { monoclonal antibody }\end{array}$ & Phase II & $\begin{array}{l}\text { PSA response, time to } \\
\text { PSA progression }\end{array}$ & $\begin{array}{l}\text { PSA decline in } 5 / 15, \\
\text { minimal impact on } \\
\text { disease course }\end{array}$ \\
\hline Erlotinib [56] & $\begin{array}{l}\text { Tyrosine kinase } \\
\text { inhibitor against } \\
\text { EGFR }\end{array}$ & Phase II & PSA response rate & Completed, no report \\
\hline Lanreotide [57] & Somatostatin analog & $\begin{array}{l}\text { CAB vs. CAB plus } \\
\text { lanreotide }\end{array}$ & PFS & $\begin{array}{l}\text { Terminated early (poor } \\
\text { accrual) }\end{array}$ \\
\hline Octreotide [58] & Somatostatin analog & Phase II & PSA response & $\begin{array}{l}\text { Terminated early (no PSA } \\
\text { response on interim } \\
\text { analysis) }\end{array}$ \\
\hline Cilengitide [59] & Integrin antagonist & Phase II & PSA response & $\begin{array}{l}\text { No PSA response (decline } \\
\geq 50 \% \text { ) }\end{array}$ \\
\hline
\end{tabular}

BMFS, bone-metastasis-free survival; MFS, metastasis-free survival; CAB, combined androgen blockade; EGFR, epidermal growth factor receptor; NM-CRPC, nonmetastatic castration-resistant prostate cancer; OS, overall survival; PFS, progression-free survival; PSA, prostate-specific antigen; TTP, time to disease progression; VEGF, vascular endothelial growth factor.

$\leq 6$ months, 18.3 months for PSA-DT $\leq 4$ months).

\section{TREATMENTS}

Since the approval of docetaxel for the treatment of CRPC in 2004 [15], dramatic changes have taken place in the agents approved for men with CRPC. However, these newer treatments were developed in the clinical context of advanced CRPC and not NM-CRPC. It should be noted that the clinical end points in studies involving advanced CRPC and NM-CRPC differ. In advanced metastatic CRPC patients, pain and quality of life are the overriding factors [16]. In contrast, delaying time to progression is more important in nonmetastatic or oligo-metastatic CRPC groups. Notwithstanding these differences, no treatment options outside the context of clinical trials including cytotoxic therapy are currently recommended for NM-CRPC in most guidelines [8] because there are no randomized trials showing an OS benefit in these patients (Table 1). For example, the NCCN guideline recommends clinical trials as a preferred choice and observation as another option in men with NM-CRPC [17]. The American Urological Association (AUA) guideline likewise recommends ob- servation with continued ADT, although the evidence for maintaining ADT is weak (grade C) [18]. Given the lack of clinical trials in NM-CRPC, clinicians are left to choose the best treatment options in these men on the basis of the studies in patients with metastatic CRPC.

\section{Salvage radiotherapy}

A minority of patients with localized cancer are treated with primary ADT. Most of these patients eventually develop a rising PSA. Botticella et al. [19] retrospectively evaluated the potential benefit of external beam radiotherapy (EBRT) in this cohort. The median duration of primary ADT was 54 months and the median follow-up after EBRT was 53 months. Fifty percent (21/42) developed biochemical failure (by the Phoenix criteria) after EBRT (median time, 27 months), 13 presented with regional or distant metastases, and in 8 patients, only a rise in PSA was observed. The 5-year biochemical disease-free survival (bDFS) and metastasis-free survival were $39 \%$ and $60 \%$, respectively. In the multivariate analysis, Gleason score, PSA nadir, and pre-EBRT PSA $\leq 5 \mathrm{ng} / \mathrm{mL}$ predicted bDFS. Therefore, EBRT may be an effective therapeutic option with systemic disease control in up to $60 \%$ of patients. 


\section{Salvage prostatectomy}

Gontero et al. [20] conducted a prospective study of the role of salvage radical prostatectomy in 12 patients with NM-CRPC following primary radiotherapy. Median time from radiotherapy to the development of NM-CRPC was 49 months and the median PSA at salvage surgery was 6.3 $\mathrm{ng} / \mathrm{mL}$. The pathological results revealed pT3/pT4 disease in $11, \mathrm{pN} 1$ in 6 , and positive margins in 7 . At a median follow-up of 41 months, 3 of 12 patients (25\%) had no evidence of disease, 1 showed biochemical failure only, 2 developed metastatic diseases, and 6 died of disease. Rectal injury (1) and recto-urethral fistula (1) were the major complications that occurred more frequently than expected in hormone-naive patients [21]. Accordingly, salvage prostatectomy may benefit some patients with NM-CRPC but further studies are needed to better define the selection criteria.

\section{Antiandrogen withdrawal and switching antiandrogen} When a patient treated with a combination of an antiandrogen and an LH-RH agonist develops CRPC, discontinuing the antiandrogen may suppress androgen receptor (AR) activity and induce a decline in the PSA level, which is known as antiandrogen withdrawal phenomenon. In such patients, antiandrogen is thought to exert agonistic activity on PCa cells. Fifteen to thirty percent of patients may have decline in PSA value of greater than $50 \%$ with a median duration of 3.5 to 5 months [22,23]. In a multi-institutional prospective trial (Southwest Oncology Group 9426), $21 \%$ had PSA decline of $\geq 50 \%$ and the median progression-free survival (PFS) was 3 months [24]. Multivariate analyses showed that in men with nonmetastatic, PSA-only-progression CRPC, a longer duration of antiandrogen use and lower PSA at baseline were associated with both longer PFS and OS. These results indicate that antiandrogen withdrawal phenomenon often occurs in NM-CRPC and after a long period of ADT.

Suzuki et al. [25] reported on patients with advanced $\mathrm{PCa}$ who were initially treated with combined androgen blockade . In that study, antiandrogen was discontinued and switched to an alternative antiandrogen (i.e., bicalutamide to flutamide and flutamide to bicalutamide) in patients who relapsed while on first-line therapy. Of 232 patients, $61 \%$ showed significant PSA response and better survival with the alternative antiandrogen. Similarly, another multicenter trial from Japan showed that in patients with CRPC who were initially treated with bicalutamide, second-line hormonal therapy using flutamide resulted in a PSA response in 14 of 16 patients (87.5\%) [26]. A PSA decline of $>50 \%$ was observed in $50 \%$ and the median duration of PSA response was 6.3 months.

Lodde et al. [27] conducted a prospective study with high-dose bicalutamide $(150 \mathrm{mg})$ in NM-CRPC patients. The median follow-up was 34.5 months. A PSA decline was observed in $44.7 \%$ (PSA decline from baseline $\geq 85 \%$ in $18.4 \%$, decline of $50 \%-85 \%$ in $26.3 \%$ ). The median duration of response was 18.5 months for partial and 37.4 months for complete responders. The median time to metastasis was 52.5 months for responders and 15.7 months for nonresponders.

The Therapy Assessed by Rising PSA study is ongoing in the United States and Canada in patients with rising PSA while on LH-RH agonists [28]. Patients are randomized in a double-blind fashion to dutasteride $3.5 \mathrm{mg}$ plus bicalutamide $50 \mathrm{mg}$ or placebo plus bicalutamide $50 \mathrm{mg}$ daily. The primary end point is time to disease progression.

The AUA guideline acknowledged that some patients with NM-CRPC might be uncomfortable with ADT alone and wish to initiate additional treatment despite the lack of convincing evidence. In this circumstance, clinicians may offer second-line antiandrogens or first-generation androgen synthesis inhibitors (ketoconazole+steroid) [18]. However, note that ketoconazole has been banned since 2013 in many countries owing to the risk of serious liver injury $[28,29]$.

\section{LH-RH agonists}

There are many hypotheses concerning the pathogenesis of CRPC and late reactivation of AR. One is testosterone breakthrough or breakthrough escape [30]. According to this concept, LH-RH receptors become less sensitive to the drug with time, leading to decreased activity of the drug and subsequent increased testosterone production. In these patients with testosterone breakthrough, the serum testosterone level is high. In contrast, the cancer has become hormone independent if serum testosterone is low. A study from Spain determined that the lowest testosterone level with a significant impact on survival free of progression is $32 \mathrm{ng} / \mathrm{dL}$ [31]. The mean PFS in patients with breakthrough serum testosterone increases greater than $32 \mathrm{ng} / \mathrm{dL}$ was 88 months, whereas it was 137 months in those without the breakthrough $(p<0.03)$. Lawrentschuk et al. [32] performed another study of the efficacy of second-line LH-RH agonist after PSA progression. Of 39 men, 27 (69\%) had decreased PSA after 3 months of switching drugs and the median time to a subsequent PSA increase was 5.2 months.

\section{Bone-targeted agents}

In most NM-CRPC, the most common first metastatic lesion detected is bone metastasis. Therefore, many prospective trials have been conducted on the potential benefit of bone-targeted agents.

Clodronate, a first-generation bisphosphonate, had been reported to improve outcomes of patients with breast cancer. Therefore, a randomized double-blind placebo-controlled trial was performed with clodronate in patients with high-risk nonmetastatic PCa from 1994 [33]. After a median follow-up of 9.8 years, clodronate was shown to have no effect on BMFS or OS. The more recent update with a follow-up period of 12 years demonstrated similar results [34].

Smith et al. [10] performed a randomized controlled trial to evaluate the effects of zoledronic acid on time to first bone 
metastasis in NM-CRPC patients. However, this study was terminated before completion of accrual after interim analyses showed that the observed event occurred less frequently than expected.

Nelson et al. [35] carried out a similarly randomized controlled trial with atrasentan, a selective endothelin-A (ETA) receptor antagonist, in NM-CRPC patients. On the basis of the zoledronic acid study, the authors applied more strict inclusion criteria. Before randomization, PSA levels were $\geq 20 \mathrm{ng} / \mathrm{mL}$ within 12 months or had increased by $50 \%$ within 6 months (minimum of $1.0 \mathrm{ng} / \mathrm{mL}$ at screening) or were rising (two sequential increases) within 12 months. Atrasentan lengthened PSA-DT $(\mathrm{p}=0.031)$ but did not significantly delay the time to disease progression $(\mathrm{p}=0.288)$.

Miller et al. [36] investigated another ETA receptor antagonist, zibotentan (ZD4054), in NM-CRPC. In the interim analysis, zibotentan did not significantly improve OS $(p=0.589)$ or PFS $(p=0.330)$ and the trial was terminated early.

The most recent clinical trial in NM-CRPC investigated the effect of denosumab, an anti-RANK ligand monoclonal antibody, on prevention of bone metastasis or death [37]. Those investigators selected patients with a high risk of bone metastasis (PSA $\geq 8.0 \mathrm{ng} / \mathrm{ml}$, PSA-DT $\leq 10$ months, or both). Denosumab significantly increased BMFS compared with placebo ( 29.5 months vs. 25.2 months, $\mathrm{p}=0.028$ ) and delayed time to first bone metastasis (33.2 months vs. 29.5 months, $\mathrm{p}=0.032$ ); however, OS did not differ significantly between groups. The most concerning complication in this study was the $5 \%$ incidence of osteonecrosis of the jaw. Despite the statistically significant improvement, the impact of delaying metastases by 4 months must await additional follow-up considering the long natural history of NM-CRPC. Currently, denosumab is not recommended by the AUA in NM-CRPC patients [18].

\section{Immunotherapy: cancer vaccine}

Madan et al. [38] reported a randomized trial with poxvirus-based PSA vaccine, nilutamide, or the combination in 42 patients with NM-CRPC. Median survival exhibited a trend toward improvement for patients initially randomized to the vaccine arm (median, 5.1 years vs. 3.4 years; $\mathrm{p}=0.13$ ). A subset of 12 patients who initially received the vaccine and then later received nilutamide suggested improved survival compared with the 8 patients who began with nilutamide and were subsequently treated with vaccine (median, 6.2 years vs. 3.7 years; $\mathrm{p}=0.045$ ).

Sipuleucel-T is an active cellular immunotherapy. In 2010, the Food and Drug Administration approved sipuleucel-T (Provenge) for the treatment of asymptomatic or minimally symptomatic metastatic CRPC on the basis of three randomized clinical trials that included 737 participants [39-41]. OS improved significantly with sipuleucel-T compared with that in the control group (hazard ratio [HR], 0.73; $p=0.001)$, but time to disease progression was not prolonged (HR, $0.89 ; \mathrm{p}=0.18$ ). This discrepancy may be explained in part by the delayed onset of antitumor re- sponses after active immunotherapy, relative to objective disease progression, which occurred early [42].

As suggested by these two studies, immunotherapy is expected to have a role in the treatment of NM-CRPC, but no RCT is currently being conducted.

\section{New antiandrogens}

Newer agents investigated or approved for metastatic CRPC have been in trials for NM-CRPC patients. One published report of abiraterone (Zytiga) and prednisone included men with NM-CRPC [43]. However, only 4 men with NM-CRPC were included in this study.

A multinational, phase III, randomized placebo-controlled trial (PROSPER Trial) with enzalutamide (Xtandi) was started in 2013 [44]. Its primary end point was metastasis-free survival.

Simultaneously, a phase III study with ARN-509 (SPARTAN trial) was started in 2013 [45]. ARN-509 is a novel androgen receptor antagonist that is currently being investigated in patients with CRPC [46].

A phase II open-label study with orteronel (TAK-700), a 17,20-lyase inhibitor, in patients with NM-CRPC was started in 2010 and is still ongoing [47]. Its primary outcome measure is PSA response $(\leq 0.2 \mathrm{ng} / \mathrm{mL}$ following 3 months of treatment).

3,3'-Diindolylmethane, which is known to modulate estrogen metabolism and to act as an antiandrogen, was well tolerated in a phase I study with NM-CRPC patients [48]. However, no further study is in progress.

\section{Androgen}

Morris et al. [49] reported a phase I trial of high-dose exogenous testosterone in patients with metastatic CRPC. Consistent with reports of the safety of exogenous androgen priming to enhance chemotherapeutic efficacy in advanced PCa [50], Morris et al. [49]'s trial demonstrates that administration of exogenous testosterone ( 3 times the usual replacement dose of testosterone) to men with metastatic CRPC was safe, provided that very careful monitoring is used [51]. There is an ongoing, randomized phase II trial of testosterone placement (AndroGel 1\%, $10 \mathrm{~g}$ daily) in men with NM-CRPC [52]. The primary objective of that study is to determine the effect of testosterone placement on progression and time to clinical progression.

\section{Targeted molecular agents}

Bevacizumab (Avastin) is a humanized monoclonal antibody against vascular endothelial growth factor $\mathrm{A}$ and is used many metastatic cancers including renal cell carcinoma. Ogita et al. [53] reported the results of a phase II trial of bevacizumab monotherapy in NM-CRPC. Fifteen patients were enrolled and treated with bevacizumab for a median duration of 3.1 months. PSA declined in five patients during the treatment. Median time to PSA progression and new metastasis were 2.8 and 7.9 months, respectively. The authors concluded that bevacizumab therapy had a minimal impact on the disease course of 


\section{NM-CRPC.}

Erlotinib (Tarceva) is an oral tyrosine kinase inhibitor targeted against epidermal growth factor receptors. It is licensed to treat people with non-small-cell lung cancer and pancreas cancer. Erlotinib demonstrated an improvement in clinical benefit in metastatic CRPC patients $[54,55]$ and was also tried in a phase II study with NM-CRPC patients. The trial was completed but no results have been reported yet [56].

\section{Other agents}

A randomized phase III study of a somatostatin analog, lanreotide, in NM-CRPC patients with elevated levels of chromogranin A was started in 2012 [57]. The aim of this study was to compare the efficacy of lanreotide in addition to combined androgen blockade. Unfortunately, the study was terminated early owing to poor accrual. That said, another somatostatin analog, octreotide acetate, was investigated in a phase II study with NM-CRPC patients [58]. Octreotide significantly lowered insulin-like growth factor 1 and raised insulin-like growth factor binding protein 1 levels but did not result in a sustained decline in PSA.

A phase II study of Cilengitide, a selective antagonist of integrins that mediate invasion and angiogenesis in $\mathrm{PCa}$ bone metastases, was conducted in 13 NM-CRPC patients [59]. Cilengitide had no PSA responses, which suggests that circulating tumor cells are of no utility in these patients.

\section{CONCLUSIONS}

Men with NM-CRPC have a relatively prolonged natural history. During follow-up, PSA kinetics including baseline PSA, PSA-DT, and PSA velocity provide the most valuable information as to prognosis. The development of newer imaging modalities should aid in the follow-up of these patients in the near future. After the introduction of docetaxel for CRPC patients, many drugs have been developed for NM-CRPC patients. However, considering the potential adverse effects of these agents, active surveillance with or without ADT is still the treatment of choice.

\section{CONFLICTS OF INTEREST}

The authors have nothing to disclose.

\section{REFERENCES}

1. Siegel R, Ma J, Zou Z, Jemal A. Cancer statistics, 2014. CA Cancer J Clin 2014;64:9-29.

2. Jung KW, Won YJ, Kong HJ, Oh CM, Seo HG, Lee JS. Cancer statistics in Korea: incidence, mortality, survival and prevalence in 2010. Cancer Res Treat 2013;45:1-14.

3. Kim D, Choi D, Lim JH, Yoon JH, Jeong IG, You D, et al. Changes in prostate cancer aggressiveness over a 12 -year period in Korea. Korean J Urol 2012;53:680-5.

4. Scher HI, Halabi S, Tannock I, Morris M, Sternberg CN, Carducci MA, et al. Design and end points of clinical trials for patients with progressive prostate cancer and castrate levels of testosterone: recommendations of the Prostate Cancer Clinical Trials Working Group. J Clin Oncol 2008;26:1148-59.

5. Akaza $\mathrm{H}$. Asian trends in primary androgen depletion therapy on prostate cancer. Cancer Biol Med 2013;10:187-91.

6. Kirby M, Hirst C, Crawford ED. Characterising the castration-resistant prostate cancer population: a systematic review. Int J Clin Pract 2011;65:1180-92.

7. Kim SJ, Kim SI. Current treatment strategies for castration-resistant prostate cancer. Korean J Urol 2011;52:157-65.

8. Heidenreich A, Bastian PJ, Bellmunt J, Bolla M, Joniau S, van der Kwast T, et al. EAU Guidelines on Prostate Cancer. Part II: Treatment of Advanced, Relapsing, and Castration-Resistant Prostate Cancer. Eur Urol 2014;65:467-79.

9. Bubley GJ, Carducci M, Dahut W, Dawson N, Daliani D, Eisenberger M, et al. Eligibility and response guidelines for phase II clinical trials in androgen-independent prostate cancer: recommendations from the Prostate-Specific Antigen Working Group. J Clin Oncol 1999;17:3461-7.

10. Smith MR, Kabbinavar F, Saad F, Hussain A, Gittelman MC, Bilhartz DL, et al. Natural history of rising serum prostate-specific antigen in men with castrate nonmetastatic prostate cancer. J Clin Oncol 2005;23:2918-25.

11. Smith MR, Cook R, Lee KA, Nelson JB. Disease and host characteristics as predictors of time to first bone metastasis and death in men with progressive castration-resistant nonmetastatic prostate cancer. Cancer 2011;117:2077-85.

12. Tombal B, Lecouvet F. Modern detection of prostate cancer's bone metastasis: is the bone scan era over? Adv Urol 2012;2012: 893193.

13. Yu EY, Miller K, Nelson J, Gleave M, Fizazi K, Moul JW, et al. Detection of previously unidentified metastatic disease as a leading cause of screening failure in a phase III trial of zibotentan versus placebo in patients with nonmetastatic, castration resistant prostate cancer. J Urol 2012;188:103-9.

14. Smith MR, Saad F, Oudard S, Shore N, Fizazi K, Sieber P, et al. Denosumab and bone metastasis-free survival in men with nonmetastatic castration-resistant prostate cancer: exploratory analyses by baseline prostate-specific antigen doubling time. J Clin Oncol 2013;31:3800-6.

15. Tannock IF, de Wit R, Berry WR, Horti J, Pluzanska A, Chi KN, et al. Docetaxel plus prednisone or mitoxantrone plus prednisone for advanced prostate cancer. N Engl J Med 2004;351:1502-12.

16. Tombal B. Non-metastatic CRPC and asymptomatic metastatic CRPC: which treatment for which patient? Ann Oncol 2012;23 Suppl 10:x251-8.

17. NCCN clinical practice guideline in oncology: prostate cancer, version 4.2013 [Internet]. Fort Wathington: National Comprehensive Cancer Network; c2012 [cited 2014 Jan 14]. Available from: http://www.nccn.org/professionals/physician_gls/pdf/prostate.pdf.

18. Cookson MS, Roth BJ, Dahm P, Engstrom C, Freedland SJ, Hussain M, et al. Castration-resistant prostate cancer: AUA Guideline. J Urol 2013;190:429-38.

19. Botticella A, Guarneri A, Filippi AR, Levra NG, Munoz F, Ragona $\mathrm{R}$, et al. May non-metastatic clinically localized castration-resistant prostate cancer after primary androgen ablation benefit from salvage prostate radiotherapy? J Cancer Res Clin Oncol 2013;139:1955-60.

20. Gontero P, Spahn M, Marchioro G, Karnes JR, Briganti A, Frea $\mathrm{B}$, et al. Salvage radical prostatectomy in nonmetastatic castration-resistant prostate cancer patients who received previous radiotherapy: a feasibility study. Eur Urol 2014;65:254-5.

21. Chade DC, Eastham J, Graefen M, Hu JC, Karnes RJ, Klotz L, 
et al. Cancer control and functional outcomes of salvage radical prostatectomy for radiation-recurrent prostate cancer: a systematic review of the literature. Eur Urol 2012;61:961-71.

22. Kelly WK, Scher HI. Prostate specific antigen decline after antiandrogen withdrawal: the flutamide withdrawal syndrome. J Urol 1993;149:607-9.

23. Small EJ, Carroll PR. Prostate-specific antigen decline after casodex withdrawal: evidence for an antiandrogen withdrawal syndrome. Urology 1994;43:408-10.

24. Sartor AO, Tangen CM, Hussain MH, Eisenberger MA, Parab M, Fontana JA, et al. Antiandrogen withdrawal in castrate-refractory prostate cancer: a Southwest Oncology Group trial (SWOG 9426). Cancer 2008;112:2393-400.

25. Suzuki H, Okihara K, Miyake H, Fujisawa M, Miyoshi S, Matsumoto T, et al. Alternative nonsteroidal antiandrogen therapy for advanced prostate cancer that relapsed after initial maximum androgen blockade. J Urol 2008;180:921-7.

26. Narimoto K, Mizokami A, Izumi K, Mihara S, Sawada K, Sugata $\mathrm{T}$, et al. Adrenal androgen levels as predictors of outcome in castration-resistant prostate cancer patients treated with combined androgen blockade using flutamide as a second-line anti-androgen. Int J Urol 2010;17:337-45.

27. Lodde M, Lacombe L, Fradet Y. Salvage therapy with bicalutamide $150 \mathrm{mg}$ in nonmetastatic castration-resistant prostate cancer. Urology 2010;76:1189-93.

28. Sartor O, Gomella LG, Gagnier P, Melich K, Dann R. Dutasteride and bicalutamide in patients with hormone-refractory prostate cancer: the Therapy Assessed by Rising PSA (TARP) study rationale and design. Can J Urol 2009;16:4806-12.

29. European Medicines Agency recommends suspension of marketing authorisations for oral ketoconazole [Internet]. London:

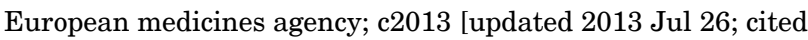
2014 Jan 19]. Available from: http://www.ema.europa.eu/ema/index.jsp?curl=pages/news_and_events/news/2013/07/news_detail_001855.jsp.

30. Tombal B, Berges R. Optimal control of testosterone: a clinical case-based approach of modern androgen-deprivation therapy. Eur Urol Suppl 2008;7:15-21.

31. Morote J, Orsola A, Planas J, Trilla E, Raventos CX, Cecchini L, et al. Redefining clinically significant castration levels in patients with prostate cancer receiving continuous androgen deprivation therapy. J Urol 2007;178:1290-5.

32. Lawrentschuk N, Fernandes K, Bell D, Barkin J, Fleshner N. Efficacy of a second line luteinizing hormone-releasing hormone agonist after advanced prostate cancer biochemical recurrence. J Urol 2011;185:848-54.

33. Mason MD, Sydes MR, Glaholm J, Langley RE, Huddart RA, Sokal M, et al. Oral sodium clodronate for nonmetastatic prostate cancer--results of a randomized double-blind placebo-controlled trial: Medical Research Council PR04 (ISRCTN61384873). J Natl Cancer Inst 2007;99:765-76.

34. Dearnaley DP, Mason MD, Parmar MK, Sanders K, Sydes MR. Adjuvant therapy with oral sodium clodronate in locally advanced and metastatic prostate cancer: long-term overall survival results from the MRC PR04 and PR05 randomised controlled trials. Lancet Oncol 2009;10:872-6.

35. Nelson JB, Love W, Chin JL, Saad F, Schulman CC, Sleep DJ, et al. Phase 3, randomized, controlled trial of atrasentan in patients with nonmetastatic, hormone-refractory prostate cancer. Cancer 2008;113:2478-87.

36. Miller K, Moul JW, Gleave M, Fizazi K, Nelson JB, Morris T, et al. Phase III, randomized, placebo-controlled study of once-daily oral zibotentan (ZD4054) in patients with non-metastatic castration-resistant prostate cancer. Prostate Cancer Prostatic Dis 2013;16:187-92.

37. Smith MR, Saad F, Coleman R, Shore N, Fizazi K, Tombal B, et al. Denosumab and bone-metastasis-free survival in men with castration-resistant prostate cancer: results of a phase 3 , randomised, placebo-controlled trial. Lancet 2012;379:39-46.

38. Madan RA, Gulley JL, Schlom J, Steinberg SM, Liewehr DJ, Dahut WL, et al. Analysis of overall survival in patients with nonmetastatic castration-resistant prostate cancer treated with vaccine, nilutamide, and combination therapy. Clin Cancer Res 2008;14:4526-31.

39. Higano CS, Schellhammer PF, Small EJ, Burch PA, Nemunaitis $\mathrm{J}$, Yuh L, et al. Integrated data from 2 randomized, double-blind, placebo-controlled, phase 3 trials of active cellular immunotherapy with sipuleucel-T in advanced prostate cancer. Cancer 2009;115:3670-9.

40. Kantoff PW, Higano CS, Shore ND, Berger ER, Small EJ, Penson $\mathrm{DF}$, et al. Sipuleucel-T immunotherapy for castration-resistant prostate cancer. N Engl J Med 2010;363:411-22.

41. Small EJ, Schellhammer PF, Higano CS, Redfern $\mathrm{CH}$, Nemunaitis JJ, Valone FH, et al. Placebo-controlled phase III trial of immunologic therapy with sipuleucel-T (APC8015) in patients with metastatic, asymptomatic hormone refractory prostate cancer. J Clin Oncol 2006;24:3089-94.

42. Kawalec P, Paszulewicz A, Holko P, Pilc A. Sipuleucel-T immunotherapy for castration-resistant prostate cancer. A systematic review and meta-analysis. Arch Med Sci 2012;8:767-75.

43. Attard G, Reid AH, A'Hern R, Parker C, Oommen NB, Folkerd $\mathrm{E}$, et al. Selective inhibition of CYP17 with abiraterone acetate is highly active in the treatment of castration-resistant prostate cancer. J Clin Oncol 2009;27:3742-8.

44. Safety and efficacy study of enzalutamide in patients with nonmetastatic castration-resistant prostate cancer (PROSPER) [Internet]. Bethesda: U.S. National Institutes of Health; c2013 [updated 2014 Jan 7; cited 2014 Jan 16]. Available from: http://clinicaltrials.gov/show/NCT02003924.

45. A study of ARN-509 in men with non-metastatic castration-resistant prostate cancer (SPARTAN) [Internet]. Bethesda: U.S. National Institutes of Health; c2013 [updated $2014 \mathrm{Jan} 9$; cited $2014 \mathrm{Jan} 18$ ]. Available from: http://clinicaltrials.gov/show/NCT01946204.

46. Rathkopf DE, Morris MJ, Fox JJ, Danila DC, Slovin SF, Hager $\mathrm{JH}$, et al. Phase I study of ARN-509, a novel antiandrogen, in the treatment of castration-resistant prostate cancer. J Clin Oncol 2013;31:3525-30.

47. Safety and efficacy study of TAK-700 in patients with nonmetastatic castration-resistant prostate cancer and a rising prostate-specific antigen [Internet]. Bethesda: U.S. National Institutes of Health; c2010 [updated 2013 Nov 15; cited 2014 Jan 18]. Available from: http://clinicaltrials.gov/show/NCT01046916.

48. Heath EI, Heilbrun LK, Li J, Vaishampayan U, Harper F, Pemberton $\mathrm{P}$, et al. A phase I dose-escalation study of oral BR-DIM (BioResponse 3,3'- Diindolylmethane) in castrate-resistant, non-metastatic prostate cancer. Am J Transl Res 2010;2: 402-11.

49. Morris MJ, Huang D, Kelly WK, Slovin SF, Stephenson RD, Eicher C, et al. Phase 1 trial of high-dose exogenous testosterone in patients with castration-resistant metastatic prostate cancer. Eur Urol 2009;56:237-44.

50. Manni A, Bartholomew M, Caplan R, Boucher A, Santen R, Lipton A, et al. Androgen priming and chemotherapy in advanced prostate cancer: evaluation of determinants of clinical outcome. J Clin 
Oncol 1988;6:1456-66.

51. Gardiner RA, Sweeney C, Tilley WD. Testosterone therapy in castrate-resistant prostate cancer: a possible new approach. Eur Urol 2009;56:245-6.

52. A randomized, double blind, placebo-controlled phase II study of testosterone replacement in men with non-metastatic castrate resistant prostate cancer [Internet]. Bethesda: U.S. National Institutes of Health; c2007 [updated 2014 Jan 16; cited 2014 Jan 25]. Available from: http://clinicaltrials.gov/ct2/show/NCT00515112.

53. Ogita S, Tejwani S, Heilbrun L, Fontana J, Heath E, Freeman S, et al. Pilot phase II trial of bevacizumab monotherapy in nonmetastatic castrate-resistant prostate cancer. ISRN Oncol 2012;2012:242850

54. Gravis G, Bladou F, Salem N, Goncalves A, Esterni B, Walz J, et al. Results from a monocentric phase II trial of erlotinib in patients with metastatic prostate cancer. Ann Oncol 2008;19: 1624-8.

55. Nabhan C, Lestingi TM, Galvez A, Tolzien K, Kelby SK, Tsarwhas $\mathrm{D}$, et al. Erlotinib has moderate single-agent activity in chemotherapy-naive castration-resistant prostate cancer: final results of a phase II trial. Urology 2009;74:665-71.

56. Study of erlotinib in patients with non-metastatic prostate cancer with a rising prostate specific antigen (PSA) on hormone therapy [Internet]. Bethesda: U.S. National Institutes of Health; c2005 [updated 2011 Jun 24; cited 2014 Jan 25]. Available from: http://clinicaltrials.gov/ct2/show/study/NCT00148772.

57. Study of lanreotide in non metastatic castration-resistant prostate cancer patients (POSEIDON) [Internet]. Bethesda: U.S. National Institutes of Health; c2011 [updated 2013 Apr 23; cited 2014 Jan 18]. Available from: http://clinicaltrials.gov/show/NCT01313273.

58. Friedlander TW, Weinberg VK, Small EJ, Sharib J, Harzstark $\mathrm{AL}$, Lin AM, et al. Effect of the somatostatin analog octreotide acetate on circulating insulin-like growth factor-1 and related peptides in patients with non-metastatic castration-resistant prostate cancer: results of a phase II study. Urol Oncol 2012;30:408-14

59. Alva A, Slovin S, Daignault S, Carducci M, Dipaola R, Pienta K, et al. Phase II study of cilengitide (EMD 121974, NSC 707544) in patients with non-metastatic castration resistant prostate cancer, NCI- 6735 . A study by the DOD/PCF prostate cancer clinical trials consortium. Invest New Drugs 2012;30:749-57. 